\title{
Effect of load level of corner columns on punching shear resistance of flat slabs
}

\author{
Michał Gołdyn', Tadeusz Urban² \\ ${ }^{1}$ Department of Concrete Structures; Faculty of Civil Engineering, Architecture and Environmental \\ Engineering; Lodz University of Technology, 6 Politechniki Avenue, 90-924 Łódź, Poland; \\ michal.goldyn@p.lodz.pl (D)0000-0002-7791-1940 \\ ${ }^{2}$ Department of Concrete Structures; Faculty of Civil Engineering, Architecture and Environmental \\ Engineering; Lodz University of Technology, 6 Politechniki Avenue, 90-924 Łódź, Poland; \\ tadeusz.urban@p.lodz.pl (iD)0000-0001-7494-3747
}

\begin{abstract}
The problem related to the effect of the corner column load on the punching shear resistance of the slab was presented. Existing experimental studies on internal columns demonstrated that the column pressure could lead to an increase in the punching shear resistance. Because of different confinement conditions of corner column-slab connection joints, it is unclear if such an effect exists for corner columns. New experimental investigations were initiated to clarify this issue. They covered a total of three corner column-slab connection specimens - slabs with a thickness of $140 \mathrm{~mm}$ and a longitudinal reinforcement ratio $\rho_{1}=1.09 \%$ connected with columns of a cross-section of $200 \times 200 \mathrm{~mm}$. The only variable parameter was the column load equal to 500,1000 and $1500 \mathrm{kN}$.

A reduction of the slab load-carrying capacity of about $9 \%$ due to a three-fold increase in the column load was noted. Therefore, the effect of the column load turned out to be opposite to that observed for most previous tests on internal column-slab connections, which could have a result of a limited capacity of the slab reinforcement due to additional tensile forces from the lateral expansion of joint concrete.

Comparison in the light of test results demonstrated, that EN 1992-1-1 procedure allowed for safe, yet conservative estimation of the punching shear resistance. An average ratio of experimental to theoretical load of 1.82 was obtained.
\end{abstract}

Keywords: column-slab connections, punching shear, lateral expansion, membrane action, normal stress

\section{Introduction}

Column-slab structural systems owe their popularity to the freedom they give by arranging the space inside buildings. They also do not impose limitations on the usable height of the story, 
as is the case of slab-beam ceilings. A crucial area in column-slab systems is usually a support zone in which the slab, due to the concentration of internal forces, is exposed to failure due to punching. In real structures, the effects acting within support zones result not only from the load applied on the floor slab but also from the transmission of forces between the columns of subsequent floors. Therefore, the interaction of both raises a justified question about the effect on the load carrying capacity of columns and slabs of multi-storey buildings.

For economic reasons, as a rule, different classes of concrete for slabs and columns are used. Due to the different nature of the load, columns are usually made from concrete of a higher strength. The problem of load-carrying capacity of reinforced concrete columns intersected by weaker concrete slabs was the subject of relatively few works. Previous experimental investigations conducted at the Department of Concrete Structures of the Lodz University of Technology (including [1], [2]), regarding the connection of high-strength concrete columns with ordinary or lightweight aggregate concrete slabs demonstrated a significant effect of the intersection on the ultimate columns loads. The destructive forces turned out, however higher than the theoretical load-carrying capacities resulting from uniaxial compressive strength of slab concrete. This was a consequence of the limitation of lateral expansion of joint concrete by the surrounding slab (confining action), what resulted in an increase in the effective strength of slab concrete by up to $200 \div 300 \%$ compared to the uniaxial compressive strength. It should be emphasized that the beneficial effect of the confining action was also observed in the case of the external joints (edge and corner). Similar conclusions resulted from studies of Guidotti et al. [3], regarding internal column-slab connection joints. Depending on the slab longitudinal reinforcement ratio, the effective strength of the joint concrete was over $70 \div 180 \%$ higher than uniaxial one.

However, considering column-slab connections, the effect of column pressure on the load-carrying capacity of the slab cannot be ignored. On the one hand, lateral expansion of joint concrete leads to the formation of normal (compressive) stresses in the cross-section of the slab. On the other hand, it causes additional tensile forces in the longitudinal reinforcement, which yield at a lower load level. The effect of the internal column pressure on the load capacity of the slab is schematically shown in Fig. 1, including suggestions of Muttoni et al. [4].

If the load capacity of the slab is dependent on punching mechanism, then the column pressure $N_{\text {Ed }}$, inducing stress $\sigma_{\mathrm{c}}$ exceeding uniaxial compressive strength $f_{\text {cd }}$, results in lateral expansion of joint concrete and corresponding lateral stress $\sigma_{2}$. As a result of these deformations, compressive stress $\sigma_{\mathrm{cp}}$ appears in the slab. An increase in normal stress leads to an increase in the punching shear resistance $V_{\mathrm{Rd}, \mathrm{c}}\left(N_{\mathrm{Ed}}\right)$ as is observed in case of post-tensioned slabs, which was proved by research, among others [5], [6]. 


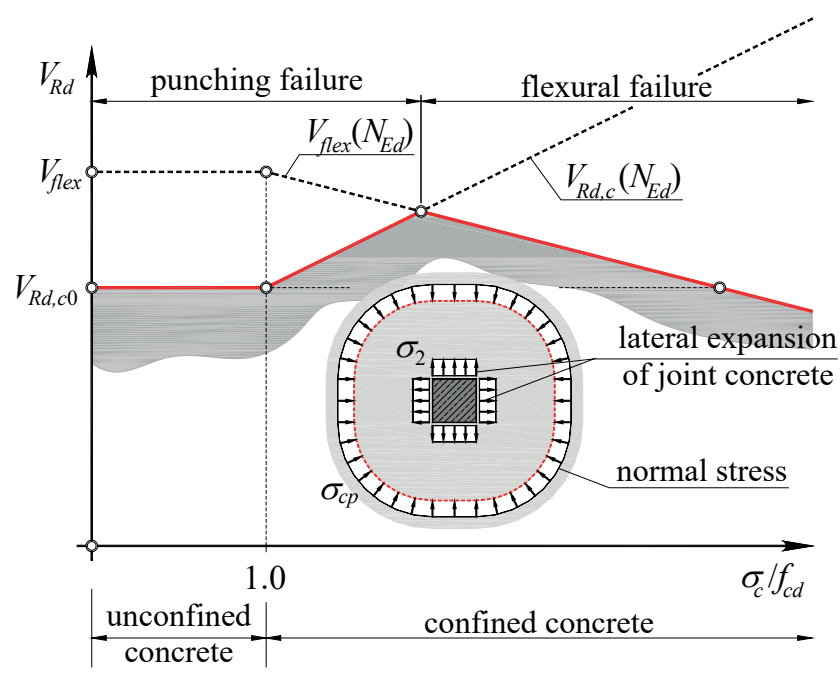

Fig. 1. Effect of column pressure on ultimate slab load. Source: own study

However, due to the lateral expansion of joint concrete in the longitudinal slab reinforcement, additional tensile forces arise. If column loads $N_{\mathrm{Ed}}$ generates stress exceeding uniaxial compressive strength of the slab concrete $\left(\sigma_{\mathrm{c}}>\mathrm{f}_{\mathrm{cd}}\right)$, then limited flexural resistance $V_{\text {flex }}\left(N_{\mathrm{Ed}}\right)$ should be expected. Depending on the intensity of the reinforcement as well as the $\sigma_{\mathrm{c}} / \mathrm{f}_{\mathrm{cd}}$ ratio, it may turn out that the flexural mechanism is decisive and the column pressure reduces the resistance of the slab due to the significant limitation of the load-carrying capacity of longitudinal reinforcement.

The issue of the interaction of column and slab load on the punching shear resistance has been so far considered only in works [3], [4]. Tests on the specimens made in real scale, characterized by longitudinal reinforcement ratios, equal to approximately $\rho_{1}=0.80 \div 1.60 \%$, demonstrated an increase in punching shear resistance reaching even over $30 \%$. This effect was dependent mainly from the ratio of stress within the column base to the uniaxial compressive strength of slab concrete. It was also found that lateral expansion of joint concrete contributed to the decrease in flexural capacity due to the increase in strains of longitudinal reinforcement, which was manifested by a significant increase in slab rotation $\psi$ (representing deflections). In the case of one of the specimens, the failure was a consequence of the flexural mechanism. However, the stress at the column base was almost three times the uniaxial compressive strength of slab concrete.

While in the case of internal connections a favourable effect of column pressure on the punching shear resistance, similar to the effect of a membrane action, can be expected, a justified question arises about external connection joints. The slab surrounds edge or corner column only from 2 or 3 sides. As a result, joint concrete is less confined, which makes it impossible to induce normal compressive stress $\sigma_{\mathrm{cp}}$ as high as in case of internal columns. Despite the great practical significance, this issue has not yet been fully explained, which was the premise for undertaking the experimental investigations at the Department of Concrete Structures of the Lodz University of Technology. 


\section{Experimental investigations}

\subsection{Test specimens}

The tests included a total of three identical models - see Fig. 2. A $140 \mathrm{~mm}$ thick slab was connected with a column of $200 \times 200 \mathrm{~mm}$ rectangular cross-section and a total height of $1340 \mathrm{~mm}$. The main reinforcement of the slab consisted in ribbed bars $\phi 10$ at $60 \mathrm{~mm}$ in both directions (mean longitudinal reinforcement ratio $\rho_{1}=1.09 \%$ ). The anchorage was carried out from the free edge using a loop. The other end of the bar was anchored by welding with perpendicular reinforcement. The nominal cover of the reinforcement resulted from the bond conditions and was $c_{\text {nom }}=10 \mathrm{~mm}$, which allowed to obtain the average effective depth $d=120 \mathrm{~mm}$. No punching shear reinforcement was placed in the slabs. Longitudinal reinforcement of the column consisted of 4 bars $\phi 20$ and stirrups $\phi 8$ at nominal spacing every $100 \mathrm{~mm}$, reduced to $50 \mathrm{~mm}$ at both ends of the column.

The models were intended to reflect column-slab connections corresponding to real structures. Therefore, they were made in three stages, consisting of casting the bottom column at the beginning, then the slab and the top column at the end. Two different concrete mixes were used. The columns were made of a concrete mix produced on-site with the designed compressive strength class $\mathrm{C} 40 / 50$, while slabs of ready-mixed concrete with the designed compressive strength class $\mathrm{C} 25 / 30$. At a given stage, individual parts of the specimens (columns and slabs) were made of concrete from a single batch.
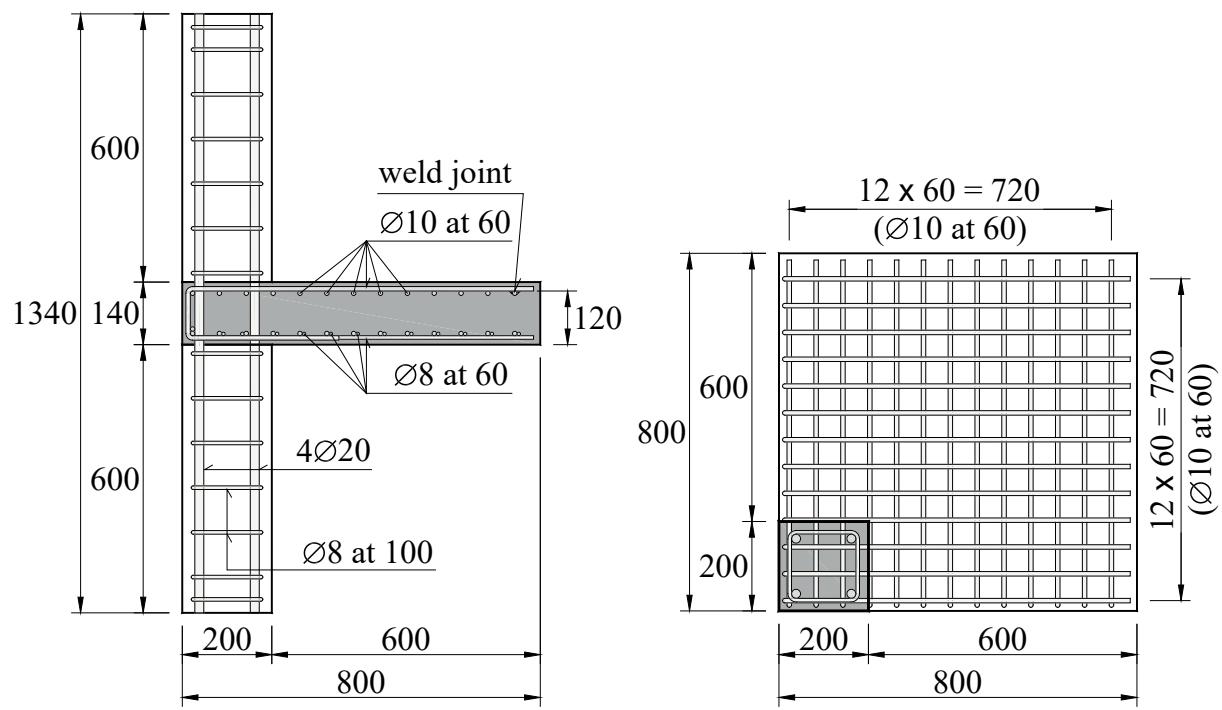

Fig. 2. View of the reinforcement of the test specimens. Source: own study

Concrete properties were determined at the day of testing of main specimens. Due to the long time that elapsed from a casting of the elements no significant differences in strength of concrete were found (coefficient of variation below 5\%), therefore, mean values were assumed for the further analysis. The compressive strengths, determined on cylindrical samples with diameter $\phi 150 \mathrm{~mm}$ and height of $300 \mathrm{~mm}$, were equal to $f_{\mathrm{cm}}=28.9 \mathrm{MPa}$ (slab), $f_{\mathrm{cm}}=55.0 \mathrm{MPa}$ (upper 
column), $f_{\mathrm{cm}}=45.5 \mathrm{MPa}$ (bottom column). The secant moduli of elasticity were: $E_{\mathrm{cm}}=23.6 \mathrm{GPa}$ (slab), $E_{\mathrm{cm}}=34.7 \mathrm{MPa}$ (bottom column).

Reinforcement was made of steel grade B500 with a ductility class C. The strength parameters were determined on three samples taken randomly from bars of each diameter. The average yield strengths were: $f_{\mathrm{ym}}=562.9 \mathrm{MPa}$ ( $\phi 10$ bars $)$ and $f_{\mathrm{ym}}=546.3 \mathrm{MPa}$ ( $\phi 20$ bars).

\subsection{Test setup and testing procedure}

The way of loading of the corner connections results in acting of the unbalanced bending moment, transmitted from the slab to the column. To balance the horizontal forces resulting from the action of the unbalanced moment, an additional reinforced concrete element connected with the tested specimen employing a steel ties, located in the upper part of the column, was used - see Fig 3a. The test setup enabled applying load on columns and slab independently. The tests were conducted in a universal testing machine with a maximum pressure of $6000 \mathrm{kN}$. The load was transferred on the columns of both elements utilizing a steel plate girder. The test was started with applying load on the column only. The total load was dependent on the assumed level of utilization of the column resistance and equal to $500 \mathrm{kN}$ (MN/1.25/L), $1000 \mathrm{kN}(\mathrm{MN} / 1.25 / \mathrm{M})$ or $1500 \mathrm{kN}(\mathrm{MN} / 1.25 / \mathrm{H})$. Including the contribution of the longitudinal reinforcement, it corresponded to stress at the column base of about 0.40 , 0.76 and $1.14 f_{\mathrm{cm}}$ (where $f_{\mathrm{cm}}$ is the average uniaxial compressive strength of the slab concrete).

The load was applied on the column gradually, with an increase of 100 or $150 \mathrm{kN}$ at every step. While increasing the load, deformation on the column surface was controlled and, if necessary, a slight adjustment of the hinge position was made to achieve a nearly axially load transmission. After reaching the assumed load level, the second phase of the test began. In this phase, only the slab load was increased while the load applied on column remained unchanged. The tests were carried out under load control. The slab was loaded using a hydraulic jack with a maximum pressure of $200 \mathrm{kN}$. The actuator was connected to the traverse, which allowed to apply the load at two-point distant of $100 \mathrm{~mm}$ from the free edges of the slab. The location of the actuator enabled to obtain a relative load eccentricity $e / c$ equal to about 1.25 (where $e$ is the distance between the axis of the column and the actuator while $c$ is the column width). The slab load was applied gradually, at $5 \mathrm{kN}$ in each step (loading rate was limited at the end of the test).

a)

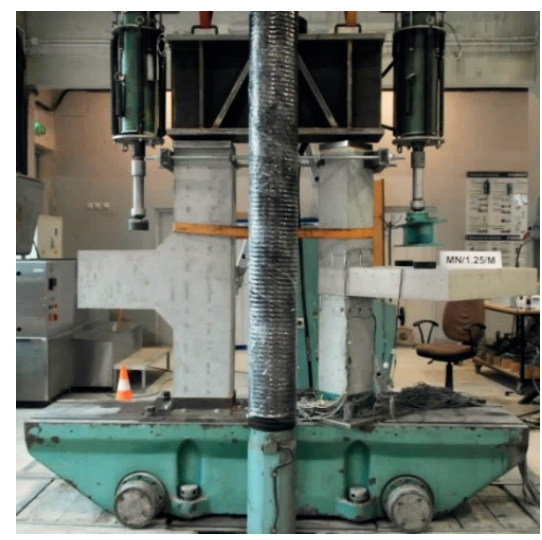

b)

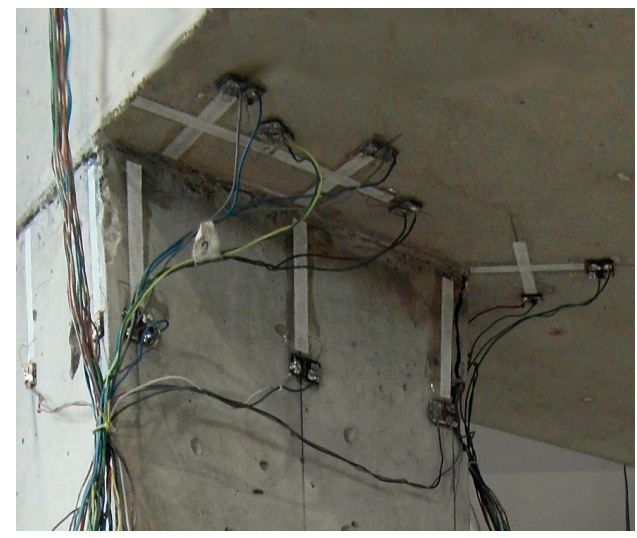

Fig. 3. The test setup and location of strain gauges. Source: own study 
After each increase in load, cracks on the upper surface of the slab were stock taken, and widths of selected cracks were measured. During the test, strains of the longitudinal slab reinforcement, as well as strains of the slab (on the bottom side only) and column surface, were also recorded - see Fig. 3b. Strain gauges were used for this purpose.

\subsection{Test results}

\subsubsection{Strains of the slab reinforcement}

During the tests, strains of the longitudinal reinforcement at the column edge were measured. Figure 4 shows the development of the strains $\varepsilon_{\mathrm{s}}$ as a function of slab load $V_{\text {slab. }}$. In the initial phase of the test, the slab remained unloaded $\left(V_{\text {slab }}=0\right)$. However, an increase in deformations was observed, which resulted only from increasing of column load. The average strains of the longitudinal reinforcement noted at the end of the first phase of the test was $\varepsilon_{\mathrm{s}, \text { init }}=-0.01,0.08$ and $0.26 \%$, for $\mathrm{MN} / 1.25 / \mathrm{L}, \mathrm{MN} / 1.25 / \mathrm{M}$ and $\mathrm{MN} / 1.25 / \mathrm{H}$ specimens respectively. A clear relationship between the column load level and initial strains in the longitudinal reinforcement was therefore visible. Although in the study corner columns, surrounded by the slab only from two sides, were considered, lateral expansion of joint concrete was stated, what was in line with the results of previous investigations concerning corner and edge columns intersected by weaker slab concrete [1]. By increasing the slab load in the next phase of the test, a further, more pronounced increase in strains was stated. In all specimens, failure was preceded by yielding of the reinforcement at the column edge. Due to initial deformation $\varepsilon_{\mathrm{s}, \text { init }}$, loads, at which the average strains reached yield strain $\varepsilon_{\mathrm{ym}}=2.80 \%$, were varied and amounted to about $100 \div 115 \mathrm{kN}(80 \div 90 \%$ of the destructive forces $V_{\text {exp }}$ ). As it comes to MN/1.25/L specimen, yielding of the reinforcement occurred at the latest, which resulted from the lack of the initial deformations due to the column load $-\varepsilon_{\mathrm{s}, \text { init }} \approx 0$.
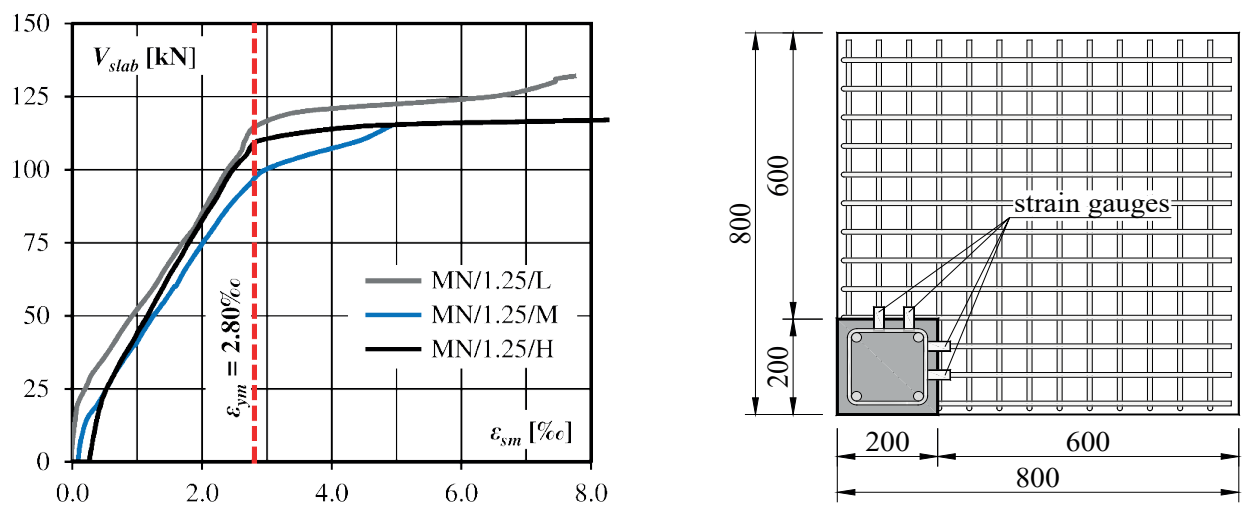

Fig. 4. Strains of the slab longitudinal reinforcement and location of the strain gauges (dashed line corresponds to yield strain). Source: own study

\subsubsection{Strains on the slab surface}

In Figure 5, the results of the strain measurements on the bottom side of the slab were presented. The deformations in the radial direction indicated tension at the initial phase of the test, what can be identified with the lateral expansion of joint concrete due 
to the column pressure. These strains depended on the column load level and were about $\varepsilon_{\mathrm{c}, \text { init }}=0.05 \div 0.37 \%$ o. Higher strains were recorded in the vicinity of the free edges of the slab (see strain gauges marked in black and the corresponding dashed lines in Fig. 5), which indicated higher deformations of the joint concrete in this area (and therefore less confinement). The increase in the slab load led to a change in the nature of the strains at a load of approximately $0.1 \div 0.4 V_{\text {exp }}$, depending on the column load level. Compression resulting from bending of the slab was recorded on the bottom surface for most of the second phase of the test.

a)

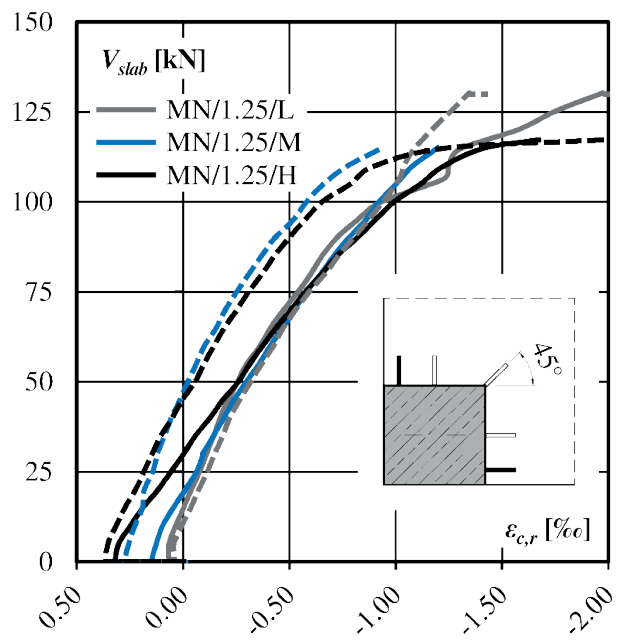

b)

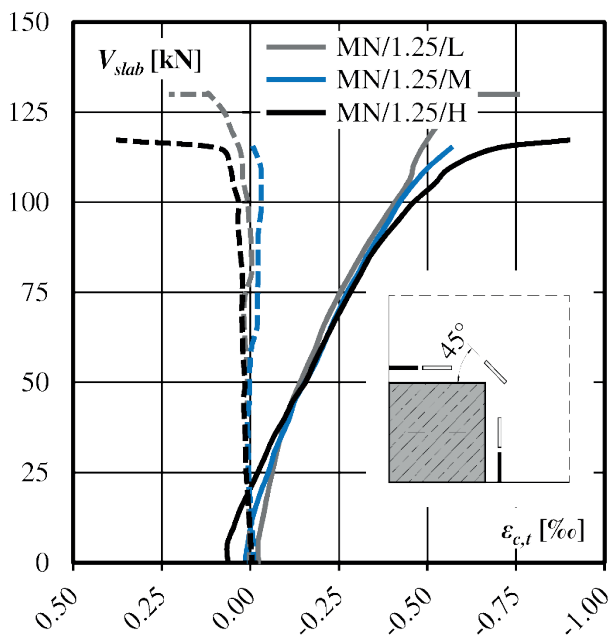

Fig. 5. Concrete strains on the compressed side of the slab: a) radial direction, b) tangential direction; (dashed lines correspond to external strain gauges marked with black). Source: own study

Comparing the strain development in the tangential direction, one can notice its different intensity in the vicinity of the inner corner of the column and the free edges of the slab. In the first location, a uniform increase in deformation was observed from the beginning of the second phase of the test. However, in the vicinity of the free edge, they remained almost unchanged. Only in the final phase of the test, preceding failure, a significant increase in these strains, indicating tensile stress, was observed. The above may indicate the degradation of the slab stiffness associated with the formation of diagonal shear cracks and the resulting reduction in the confining action.

In Figure 6, deformations measured on the surface of the bottom and upper columns in the vicinity of the inner (dashed lines) and outer corner (solid lines) were presented. Increasing the column load led to an increase in strains. The values measured after the end of the first phase of the test were proportional to the load applied on the column and equal on average $\varepsilon_{\mathrm{c}}=-0.29,-0.60$ and $-0.90 \%$, for $\mathrm{MN} / 1.25 / \mathrm{L}, \mathrm{MN} / 1.25 / \mathrm{M}$ and $\mathrm{MN} / 1.25 / \mathrm{H}$ models respectively. Increase in slab load resulted in a change in recorded strains. In the case of MN/1.25/L and MN/1.25/M specimens, an even change in their nature was observed. Shortly before failure tensile stresses were measured, which could have resulted from the spalling of concrete cover. 
a)

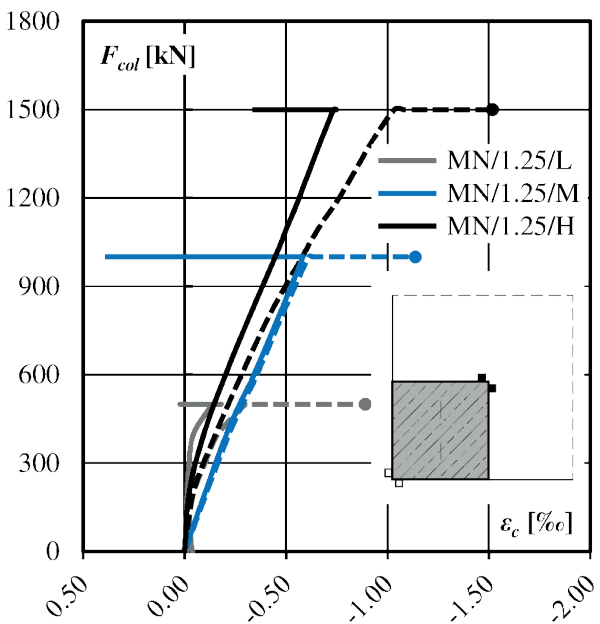

b)

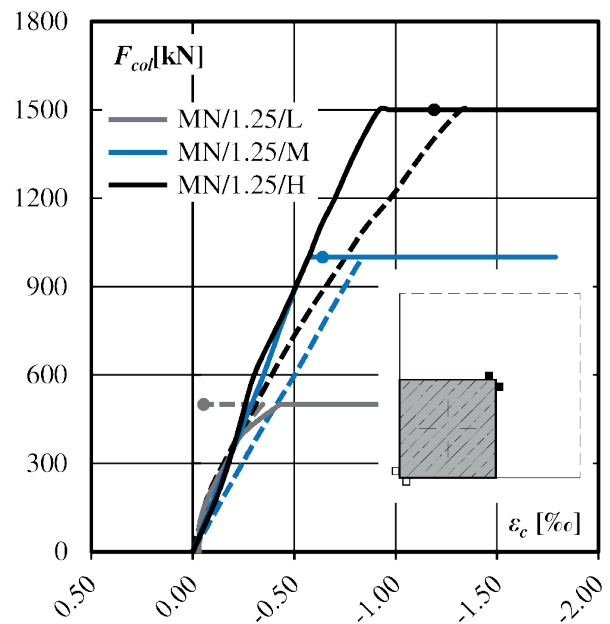

Fig. 6. Concrete strains on column surface close to corner: a) upper column, b) bottom column; (dashed lines correspond to strain gauges on the internal corner, marked with black). Source: own study

\subsubsection{Crack pattern}

Figure 7 shows the crack pattern on the upper surface of the MN/1.25/L and MN/1.25/H specimens at the same load level, equal to $V_{\text {slab }}=100 \mathrm{kN}$. Diagonal cracks, typical for external column-slab connections and resulting bending moment in the direction inclined at an angle of $45^{\circ}$ to the free edge, were visible. More intense cracking was observed in case of the $\mathrm{M} / 1.25 / \mathrm{H}$ specimen, which can be attributed to higher lateral expansion of joint concrete due to column pressure.

a)

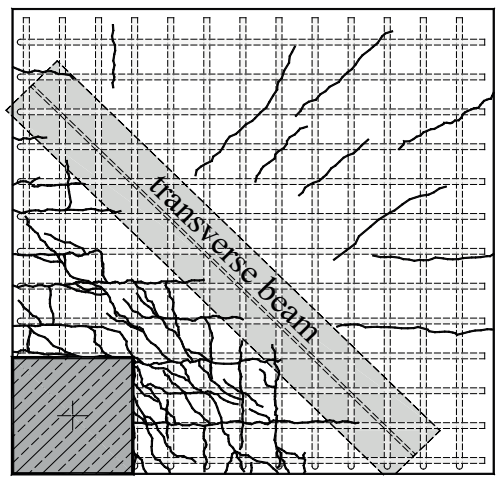

b)

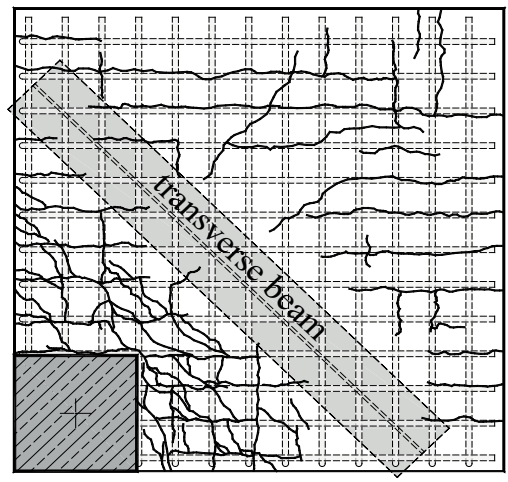

Fig. 7. Crack pattern on upper slab surface at a load of $100 \mathrm{kN}$ : a) M/1.25/L, b) M/1.25/H. Source: own study

\subsubsection{Load-carrying capacities}

The failure of all the specimens was violent, characteristic for punching shear. However, it was preceded by a noticeable slab deflections and intense cracking of the upper slab surface. This indicates that failure was a result of the combined shear and bending mechanism, which is also consistent with the assumptions of Urban's theory [7] because the mechanical reinforce- 
ment ratio was equal to $\omega=0.21<0.30$. In Figure 8 , the test results in the form of a relationship between experimental load $V_{\text {exp }}$ and applied column load $F_{\text {col }}$ were presented. Besides, the horizontal axis includes the relative stress $\sigma_{\mathrm{c}} / f_{\mathrm{cm}}$ resulting from column pressure. The total load applied on the specimens resulted in stress $\sigma_{\mathrm{c}}$ equal to $0.52,0.86$ and $1.24 f_{\mathrm{cm}}$, for $\mathrm{MN} / 1.25 / \mathrm{L}$, $\mathrm{MN} / 1.25 / \mathrm{M}$ and $\mathrm{MN} / 1.25 / \mathrm{H}$ specimens respectively.

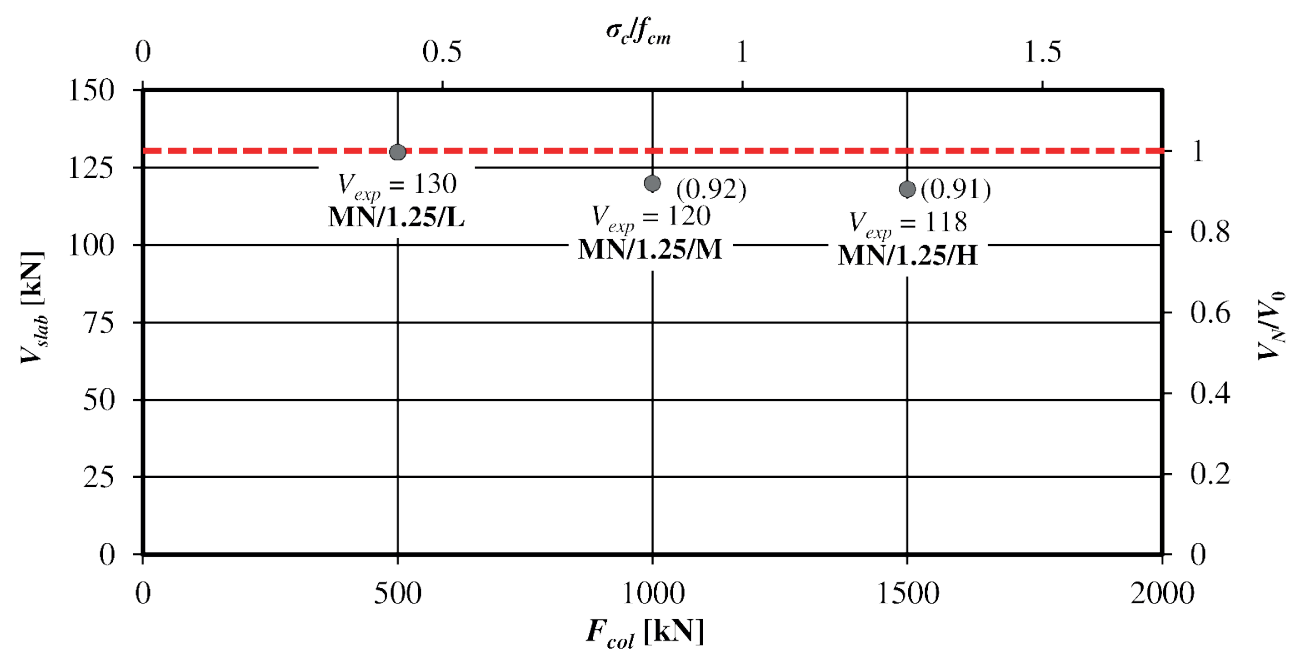

Fig. 8. Experimental loads $V_{\text {exp }}$ with respect to column load level $F_{\text {col. }}$ Source: own study

Assuming that the experimental load capacity of the MN/1.25/L specimen as a benchmark, it can be seen that an increase in the column load by 500 and $1000 \mathrm{kN}$, resulted in a reduction of the experimental loads by 7.7 and $9.2 \%$, respectively. Thus, the effect of the column load on the punching shear resistance was noticeable, although relatively small.

\section{Results of the tests in the light of Eurocode 2 provisions}

The verification of the punching shear resistance according to EN 1992-1-1 [8] consists in comparing the ultimate stress $v_{\mathrm{Rd}, \mathrm{c}}$ (expressing the load capacity) and shear stress $v_{\mathrm{Ed}}$ (representing the effects of actions). The punching shear resistance is described by eq. (1)

$$
v_{\mathrm{Rd}, \mathrm{c}}=C_{\mathrm{Rd}, \mathrm{c}} k \sqrt[3]{100 \rho_{1} f_{\mathrm{ck}}}+k_{1} \sigma_{\mathrm{cp}},
$$

where:

$C_{\mathrm{Rd}, \mathrm{c}}-$ empirical factor, equal to $0.18 / \gamma_{\mathrm{c}}$,

$\gamma_{\mathrm{c}} \quad-$ partial safety factor corresponding to concrete,

$k \quad-$ size effect factor, $k=\min \left[1+(200 / d)^{0.5} ; 2.0\right](d$ in $\mathrm{mm})$,

$\rho_{1} \quad-$ mean longitudinal reinforcement ratio, $\rho_{1} \leq 0.02$,

$f_{\text {ck }} \quad-$ concrete compressive strength,

$k_{1} \quad-$ factor equal to 0.10 ,

$\sigma_{\mathrm{cp}}-$ mean stress normal to the cross-section of the slab,

$d \quad-$ mean effective depth of the slab. 
Shear stress in the basic control section located at a distance of $2 d$ from the column face are determined according to the relationship (2). The $\beta$ coefficient expresses the effect of the unbalanced bending moment transmitted from the slab to the column on the distribution of shear stress along the control section (plastic shear stress distribution is assumed). It can be determined in a general way or by one of two simplified methods, which were discussed in more detail in [9]. Stress $v_{\mathrm{Ed}}$ is given as follows

where:

$$
v_{\mathrm{Rd}, \mathrm{c}}=\frac{\beta \cdot V_{\mathrm{ED}}}{u_{1} \cdot d},
$$

$$
\begin{aligned}
& V_{\mathrm{Ed}}-\text { shear force, } \\
& \beta-\text { increasing factor, } \\
& u_{1}-\text { length of the basic control perimeter, } \\
& d-\text { mean effective depth of the slab. }
\end{aligned}
$$

The theoretical punching shear resistances were calculated by transforming the equation (2) and substituting the ultimate shear stress, determined according to the equation (1). In the calculations, the average strength of slab concrete $\left(f_{\mathrm{cm}}\right)$ and partial safety factor $\gamma_{\mathrm{c}}=1$ were considered. Due to the constant load eccentricity $e=354 \mathrm{~mm}$, the coefficients $\beta$ were the same for all of the specimens and equal to $\beta=1.57,1.34$ and 1.5, for the general method, method of reduced control perimeters and method of constant $\beta$ factors respectively. The $\beta$ value resulting from the general method was adopted for further analysis.

The results of the calculations were presented in Table 1. As the comparison of the obtained results was made, it can be stated that the procedure of EN 1992-1-1 [8] allowed to determine the punching shear resistances in a safe but very conservative manner. Although the load capacity dropped as the column load increased, in no case did the experimental

\begin{tabular}{|c|c|c|c|c|c|c|c|c|}
\hline Specimen & $\begin{array}{l}f_{\mathrm{cm}} \\
{[\mathrm{MPa}]}\end{array}$ & $\begin{array}{l}d \\
{[\mathrm{~mm}]}\end{array}$ & $\begin{array}{l}\rho_{1} \\
{[\%]}\end{array}$ & $\begin{array}{l}u_{1} \\
{[\mathrm{~mm}]}\end{array}$ & $\begin{array}{l}u_{1^{*}} \\
{[\mathrm{~mm}]}\end{array}$ & $\begin{array}{l}V_{\text {exp }} \\
{[\mathrm{kN}]}\end{array}$ & $\begin{array}{l}V_{\text {calc }} \\
{[\mathrm{kN}]}\end{array}$ & $\frac{V_{\text {exp }}}{V_{\text {calc }}}$ \\
\hline $\mathrm{MN} / 1.25 / \mathrm{L}$ & \multirow{3}{*}{28.9} & \multirow{3}{*}{120} & \multirow{3}{*}{1.09} & \multirow{3}{*}{777} & \multirow{3}{*}{577} & 130 & \multirow{3}{*}{67.4} & 1.93 \\
\hline $\mathrm{MN} / 1.25 / \mathrm{M}$ & & & & & & 120 & & 1.78 \\
\hline $\mathrm{MN} / 1.25 / \mathrm{H}$ & & & & & & 118 & & 1.75 \\
\hline
\end{tabular}
to theoretical load ratio $V_{\text {exp }} / V_{\text {calc }}$ reach below 1.75 . This observation is consistent with the results of previous analyses presented in [9] and may indicate the conservativeness of the EN 1992-1-1 [8] procedure with respect to corner column- slab connections.

Table 1. Results of the calculations, according to EN 1992-1-1 [8] provisions. Source: own study

\section{Conclusions}

The presented experimental investigations demonstrated that the load of corner columns might affect the punching shear resistance of the slabs. However, the change in the slab load-carrying capacity resulting from a three-fold increase in the column load turned out to be low and did not exceed $10 \%$. It is worth mentioning here that the load applied on the column had an opposite effect to that observed in case of previous studies concerning internal column-slab connection joints, when an increase in the punching shear resistance was stated. In case of $\mathrm{MN} / 1.25 / \mathrm{H}$ specimen, the stress at the column base exceeded by $25 \%$ uniaxial compressive 
strength of the slab concrete, however, the beneficial effects resulting from the lateral stress due to expansion of joint concrete were not observed, as suggested by the considerations presented in Fig. 1. Measurements of the strains of longitudinal slab reinforcement indicated that additional tensile forces, which arose from the expansion of joint concrete, could prove crucial. This resulted in yielding of the reinforcement at lower load levels and thus limited flexural capacity, which turned out to be decisive in the case of failure associated with the combined shear and bending mechanism.

The analysis carried out in the light of the recommendations of EN 1992-1-1 [8] showed that the standard procedure allowed for safe but conservative estimation of the load-carrying capacities of all of the considered models. Depending on the column load level, the ratio of experimental to theoretical load $V_{\text {exp }} / V_{\text {calc }}$ equal to $1.75 \div 1.93$ was obtained. These results turned out to be similar to the findings of previous analyses presented in [9]. This may indicate a certain conservativity of the EN 1992-1-1 [8] procedure concerning corner column-slab connections. However, due to a relatively low number of tested elements, general recommendations cannot be formulated and further investigations, including among others edge connections, are needed.

\section{References}

[1] Urban T. S. and Gołdyn M.M., "Behaviour of eccentrically loaded high-strength concrete columns intersected by lower-strength concrete slabs," Structural Concrete, vol. 16, no. 4, (Dec. 2015), pp. 480-495. https://doi.org/10.1002/suco.201400114

[2] Gołdyn M. et al., "Carrying Capacity of Axially Loaded HSC Columns Intersected by NSC Slab," Architecture • Civil Engineering • Environment - ACEE, vol. 8, no. 3, (2015), pp. 51-60.

[3] Guidotti R. et al., "Crushing and flexural strength of slab-column joints," Engineering Structures, vol. 33, no. 3, (Mar. 2011), pp. 855-867. https://doi.org/10.1016/j.engstruct.2010.12.007

[4] Guidotti R. et al., "Durchstanzen von Flachdecken bei hohen Stützenlasten," Beton- und Stahlbetonbau, vol. 105, no. 1, (Jan. 2010), pp. 19-26. https://doi.org/10.1002/best.200900066

[5] Clément T. et al., "Influence of prestressing on the punching strength of post-tensioned slabs," Engineering Structures, vol. 72, (Aug. 2014), pp. 56-69. https://doi.org/10.1016/j.engstruct.2014.04.034

[6] Ramos A. P. et al., "The effect of the vertical component of prestress forces on the punching strength of flat slabs," Engineering Structures, vol. 76, (Oct. 2014), pp. 90-98. https://doi.org/10.1016/j. engstruct.2014.06.039

[7] Urban T., Przebicie w żelbecie: wybrane zagadnienia. Łódź: Zeszyty Naukowe. Rozprawy Naukowe / Politechnika Łódzka, 2005.

[8] EN 1992-1-1: Eurocode 2: Design of concrete structures - Part 1-1: General rules and rules for buildings, Brussels: European Committee for Standardisation, 2004.

[9] Gołdyn M. and Urban T., "Komentarz do zasad obliczania płyt na przebicie w strefie słupów narożnych według Eurokodu 2," Journal of Civil Engineering, Environment and Architecture, vol. 64, no. 3, (2017), pp. 235-245. https://doi.org/10.7862/rb.2017.118 
